\title{
YOUTH JUSTICE: ChALLENGES IN Responding to Young PeOPle Convicted of SeXual OfFences
}

\section{WENDY O'BRIEN*}

The clinical and criminological literature on adolescents who have committed sexual offences indicates that the pathologisation of young people and a labelling or overly punitive response is likely to be more harmful than rehabilitative. Accordingly, therapeutic counselling and diversionary schemes are seen as preferable to custodial terms in most instances. For adolescents convicted of sex offences, clinicians identify the benefits of comprehensive therapeutic care which involves family and is sensitive to the young person's context and culture. The benefits of this approach are documented and, although data are limited, indications are that recidivism is reduced where adolescents are provided with specialised counselling to encourage positive and non-abusive behaviours. In Australia, each state and territory has provisions for youth justice clients serving custodial or community orders for sexually abusive behaviours. Yet each jurisdiction experiences challenges in ensuring the delivery of equitable and comprehensive therapeutic services, particularly to regionally and remotely located youth. This paper draws on data from a national study of the therapeutic services to children and adolescents with sexualised or sexual offending behaviours. With attention to the difficulties in providing services to regionally and remotely located adolescents, this paper highlights challenges around lengthy remand terms, the provision of pre-offence diversionary programs, and the provision of specialised supervision for young people serving community orders. For example, jurisdictions with the largest geographic service areas face enormous difficulties in providing specialised supervision for community-based orders. At present, there are several jurisdictions where regionally and remotely located adolescents may serve the duration of a youth justice order without receiving specialised counselling to assist them in modifying their behaviours. The paper identifies the risks where specialised counselling cannot be provided, but also identifies specific initiatives designed to fill these gaps in service provision to youth justice clients.

\footnotetext{
* BA (Hons), PhD. Senior Research Fellow, Australian Crime Commission.
} 


\section{INTRODUCTION}

In recent years there has been a significant evolution in research and clinical interventions with children and young people with sexualised behaviours. There is now a greater understanding that young people with these behaviours are likely to have experienced childhood adversity and/or exposure to trauma. Informed by the body of work on the developmental impacts of childhood trauma, clinicians are mindful of the adverse consequences of physical abuse, sexual abuse and neglect. ${ }^{1}$ Awareness about the impacts of caregiver substance abuse, exposure to violence, social isolation, poor engagement at school and poor attachment has contributed to a context in which sexualised behaviours, particularly in young children, are often understood as 'sexually reactive' or 'acting out' responses to trauma. ${ }^{2}$ There is also an increasing understanding of the neuro-biological effects that trauma has on the developing brain, and of the need for specialised responses to children with intellectual disabilities, developmental delays and foetal alcohol syndrome.

Terminology for describing sexualised behaviours in young people remains contentious and, in Australia, debate continues as to the most appropriate terms. Whilst this may seem incidental, it is an issue of enormous significance. The terms used as descriptors can become labels that impact on how young persons consider their identity, their future, and their own potential to engage in healthy and positive behaviours. There is general consensus amongst researchers and clinicians that to refer to juveniles as 'sex offenders', 'perpetrators', or 'abusers' is stigmatising and likely to inhibit the young person's impetus to change. In general, Australian clinicians rarely use stigmatising language, particularly when referring to children below the age of criminal responsibility (under the age of 10 in Australia). ${ }^{3}$ Clinicians now

\footnotetext{
${ }^{1}$ For a discussion of attachment issues and young people with problem sexual behaviours (PSBs) or sexually abusive behaviours (SABs) see, eg, Phil Rich, Attachment and Sexual Offending: Understanding and Applying Attachment Theory to the Treatment of Juvenile Sexual Offenders (John Wiley, 2006); Cameron Boyd, 'Attachment Theory and Sexual Offending: Critical Considerations' (2007) 19 Developing Practice: The Child, Youth and Family Work Journal 44.

${ }^{2}$ For further information regarding the impacts of childhood trauma see, eg, Bessel van der Kolk, 'The Developmental Impact of Childhood Trauma' in Laurence J Kirmayer, Robert Lemelson and Mark Barad (eds), Understanding Trauma: Integrating Biological, Clinical and Cultural Perspectives (Cambridge University Press, 2007) 224.

3 A number of clinicians expressed deep concerns about the stigmatising and life-long consequences for a young person if they are placed on the Australian National Child Offender Register (ANCOR), commonly known as 'the sex offender register'. These concerns are particularly keen with respect to the registration of younger juveniles: Interview with Sue Rayment-McHugh (Griffith Youth Forensic Service, 23 June 2009); Interview with Christabel Chamarette (SafeCare, 6 May 2009).
} 
utilise terms that describe the behaviours that a young person has displayed, rather than describing the young person as something that seems pathological and intractable, that is as a 'perpetrator', or as a 'sex offender'. Children and young people with sexualised behaviours are not young paedophiles with a pre-existing or pathological sexual predilection for children. Children and young people with these behaviours are themselves likely to be victims of trauma with a series of complex and intersecting therapeutic needs.

Accurate numbers on children with sexualised or sexual offending behaviours are difficult to determine. Recent research by the Australian Institute of Criminology cites international data to estimate that sexual abuse by children or adolescents constitutes between 40 and 90 per cent of sexual offending against children. ${ }^{4}$ The breadth of this international estimate highlights the methodological challenges in pinpointing prevalence, and these data cannot be assumed to be indicative of the prevalence of childhood problem sexual behaviours in Australia. There are currently no comprehensive data indicating the prevalence of childhood sexualised behaviours in Australia, yet clinicians offering specialised counselling for these behaviours indicate that demand for services exceeds their capacity to respond. Juvenile justice data for 2006-07 indicate that 329 juveniles were adjudicated for sexual assault and other related offences, constituting only 1 per cent of the total number of juveniles adjudicated for all offence types. ${ }^{5}$ Yet these data cannot be assumed to accurately indicate either prevalence or harm, given that so few sex offences committed by young people are ever reported to police, and even fewer progress through to finalised adjudication. These challenges with data are but one indication of the complexities of responding to children and adolescents with sexualised or sexual offending behaviours, with significant challenges felt across the allied health, child protection, education and juvenile justice sectors.

This paper presents data from a national study of specialised therapeutic services to children and young people who display problem sexual behaviours or sexually abusive behaviours. ${ }^{6}$ The national study provides a broad survey of the sector, identifying major challenges and gaps in the comprehensive

\footnotetext{
${ }^{4}$ Jenny Grant et al, 'Intrafamilial Adolescent Sex Offenders' (2009) 145 Trends and Issues in Criminal Justice 1.

${ }^{5}$ Kelly Richards, 'Juveniles' Contact with the Criminal Justice System in Australia' Australian Institute of Criminology Monitoring Reports 07 (2009) 75.

${ }^{6}$ These findings are from a study undertaken by the National Indigenous Intelligence Taskforce of the Australian Crime Commission. Australia's Response to Sexualised or Sexually Abusive Behaviours in Children and Young People (2009). <http://www.crimecommission.gov.au/ publications/other/response_to_sexualised_behaviour.htm $>$.
} 
provision of specialised therapeutic services to both adjudicated and nonadjudicated children and young people with sexualised behaviours. The study identified multiple and complex impediments to the delivery of comprehensive services in this area. These challenges result in an overburdened sector that remains largely unregulated and requiring a much needed commitment to specialised training, supervision, accreditation, evaluation and ongoing research on best practice. The challenges felt by the sector also stem from a broader lack of awareness about the issue in professional contexts and Australian society more generally. Where this lack of knowledge or confidence results in non-disclosure, minimisation or stigmatisation, there will always be ongoing risks for children.

Recent Australian research provides some indication of the efficacy of therapeutic intervention with children with problem sexual behaviours, although there are few independent evaluations of these specialised counselling programs.. Counselling is thought to be effective providing it is made available early in the behavioural trajectory, the full treatment program is completed, and families are engaged in support of the young person's behavioural change. ${ }^{7}$ Despite these indications of therapeutic success, this paper identifies a number of barriers to Australian children with sexualised behaviours accessing the specialised counselling necessary for behaviour modification.

\section{A The Focus of This Paper}

For young people who have not come to the attention of the criminal justice system there are specialised tertiary services available in most metropolitan centres. Yet these metropolitan services all report an inability to respond to referral demand, and the concentration of services in the metropolitan fringe means that the vast majority of children residing in other parts of the country

\footnotetext{
${ }^{7}$ See, eg, Petra Staiger et al, A Preliminary Evaluation of the Transformers Program for Children Who Engage in Problem Sexual Behaviour (September 2005) Australian Childhood Foundation $\quad<\mathrm{http}$ //www.childhood.org.au/Assets/Files/0e1 fc3eb-578e-4abd-b308cbea4907f0aa.pdf>; Stephen Smallbone et al, 'Treatment with Youth who Have Committed Sexual Offences: Extending the Reach of Systemic Interventions through Collaborative Partnerships' (2008) 12.3 Clinical Psychologist 109; Sarah Macgregor, Sex Offender Treatment Programs: Effectiveness of Prison and Community-Based Programs in Australia and New Zealand (3 April 2008) Indigenous Justice Clearinghouse $<$ http://indigenousjustice.gov.au/briefs/brief003.pdf $>$; Jenny Thornton et al, 'Intrafamilial Adolescent Sex Offenders: Family Functioning and Treatment' (2008) 14 Journal of Family Studies 362 .
} 
have difficulty in accessing specialised services. ${ }^{8}$ In addition to these geographic gaps in service provision to community-based clients there are also instances in which strict eligibility criteria and poor referral pathways prevent young people from accessing services. The sector is hampered by funding restrictions, and an ongoing need for specialised training and workforce development. In short, there are several challenges to the comprehensive provision of therapeutic and support services to young people who have not come to the attention of the criminal justice system. Attention to these challenges is crucial in ensuring equitable and comprehensive service access and, ultimately, lessening the numbers entering the juvenile justice system.

The primary aim of this paper is to present research findings on the challenges in providing specialised tertiary services designed to effect positive behavioural change where the young person's sexualised behaviours have come to police attention. The counselling and support programs studied operate with the broad intention of diverting young people from the juvenile justice system by preventing recidivist offences. Identifying challenges in service delivery to both community-based and custodial youth clients of the criminal justice system, this paper focuses, in particular, on the impediments to providing services to regionally and remotely located youth justice clients.

\section{THERAPEUTIC JURISPRUDENCE}

The clinical and criminological literature on adolescents who have committed sexual offences indicates that overly punitive responses that pathologise and label young people are likely to be more harmful than rehabilitative. Australian and international research indicates that punitive responses to

\footnotetext{
${ }^{8}$ The few specialised services located in regional or rural parts of the country also report difficulties in adequately servicing the surrounding areas. Phoenix House, based in Bundaberg, receives calls from all over Queensland from parents, teachers and police seeking counselling for children with sexualised or sexual offending behaviours. Although Phoenix House is funded only to provide services to the Bundaberg area, its staff do offer telephone counselling - simply because of the extent of the need: Interview with Kathy Prentice (Phoenix House, Bundaberg, 24 June 2009). Rural New Street Adolescent Service was established in 2008 following a recommendation in the Aboriginal Child Sexual Assault Taskforce report that there be increased and culturally appropriate services to non-mandated youths with sexualised behaviours in rural NSW. Based in Tamworth, this service offers outreach and is described as being a state-wide service. Program staff report limitations in responding to the demand, both in rural areas, and also because of the bulk of referrals from Newcastle: Interview conducted at Rural New Street Adolescent Service, 21 April, 2009.
} 
juvenile crime are ineffective in reducing recidivism ${ }^{9}$ and greater results are achieved where an emphasis is placed on addressing the underlying and intersecting needs faced by young people.

The NSW Minister for Juvenile Justice recently commissioned a review of effective practice in juvenile justice. This report undertakes an international comparison of juvenile justice incarceration rates, finding rates of detention greatly reduced in countries that have implemented a welfare model that is based on informal interventions that prioritise young people's best interests. ${ }^{10}$ The review finds that English-speaking countries tend to work with justice models that focus on 'holding young people accountable for their actions and enforcing punitive measures through due process. ${ }^{11}$ Approaches that have been found to be more effective include the following characteristics:

Effective juvenile justice programs focus on addressing the underlying factors behind the offending behaviour of juveniles. This may involve focusing on reducing 'risk factors', such as family dysfunction, a delinquent peer group, truancy or alcohol abuse, as well as the adding or strengthening of 'protective factors' such as good parenting, having a positive role model or part-time employment. They generally emphasise the need to divert young offenders from entering the juvenile justice system. Effective responses to youth crime often include programs which deliver family, school or community-based therapies and services. ${ }^{12}$

\section{A Welfare or Justice? The Complexities of Young People's Needs}

Chris Cunneen contends that principles for Australian juvenile justice agencies have steadily moved

away from welfare-oriented approaches (with an emphasis on 'needs' over 'deeds' of the young person) to a more justice oriented approach with an

\footnotetext{
9 'Empirical studies conducted in Australia, the USA, New Zealand and Europe clearly show that traditional penal or "get tough" methods of reducing juvenile crime, such as juvenile incarceration, overly strict bail legislation, trying juveniles in adult courts, "scared straight" programs and so on, are not effective': Anthony McGinness and Tom McDermott (for Noetic Solutions Pty Ltd), Review of Effective Practice in Juvenile Justice: Report for the Minister for Juvenile Justice (January 2010), iv <http://www.djj.nsw.gov.au/pdf_htm/publications/ general/Juvenile\%20Justice\%20Effective\%20Practice\%20Review\%20FINALL.pdf $>$.

${ }^{10}$ Ibid iii.

${ }^{11}$ Ibid.

${ }^{12}$ Ibid iv.
} 
emphasis on individual responsibility, and the offence rather than the offender). ${ }^{13}$

Understandings of welfare and justice responses as mutually exclusive contribute to the ambiguity with which young people continue to be regarded under the law. The principle of doli incapax, for example, indicates the law's ambivalence regarding children's capability of knowing that their commission of a crime is wrong. For those aged 10-14, the rebuttable principle of criminal incapacity means that the prosecution of crimes committed by children in this age range is unlikely, and these children may instead be seen as in need of therapeutic, rehabilitative or practical support. As Copeland and Goodie argue, 'young people occupy an awkward social and legal space, in which they can be variously characterised as children and in need of legal protection or as adults with legal responsibilities.' 14 This 'awkward' place is one that leaves children vulnerable to discretionary processes that determine whether the child will receive a justice response or a protective intervention.

Yet analysis of the case histories of young people in contact with the criminal justice system reveals a host of intersecting and complex needs that cannot simply be characterised in terms of either welfare, or criminal justice. We know, for example, that not only are young people more likely than any other age-group to be the perpetrators of violence; they are also the age-group most likely to be victims of violence. Supported by data from the Australian Bureau of Statistics (ABS) Crime and Safety Survey $2005^{15}$ this finding is reiterated in the recent parliamentary inquiry into the impact of youth violence. ${ }^{16}$ Australian studies on the aetiological factors contributing to juvenile sexual offending reveal that young people with these behaviours are more likely to

${ }^{13}$ Chris Cunneen, 'Young People and Juvenile Justice' in Geoff Monahan and Lisa Young (eds), Children and the Law in Australia (LexisNexis, 2008) 187, 189.

${ }^{14}$ Anna Copeland and Jo Goodie, 'The Child, the Young Person and the Law' in Monahan and Young, ibid 146.

${ }^{15}$ Australian Bureau of Statistics, Crime and Safety Australia 2005, Cat No 4909.0, (2006). This survey finds that young people are most likely to be the victim of assault, with this risk decreasing in inverse proportion to their age.

${ }^{16}$ House of Representatives Standing Committee on Family, Community, Housing and Youth, Parliament of Australia, Avoid the Harm - Stay Calm: Report on the Inquiry into the Impact of Violence on Young Australians (2010) 1. In evidence to this Parliamentary Inquiry, Dr Adam Tomison, Director of the Australian Institute of Criminology, identifies that young people are more likely to be both the victims and perpetrators of violence. 'Peer on peer violence amongst young people is common. Young people are more likely than older Australians to be both the perpetrators and victims of a range of violent offences, including assault, sexual offences and homicide. Our understanding about the peer on peer violence is emerging and the AIC believes this is the key area to understand if impacts of violence on young Australians are to be reduced': at 20. 
have experienced a host of challenges in their young lives, including exposure to violence, childhood trauma, and caregiver substance abuse. More commonly understood as correlative in their effects than causal, the commonality of these histories amongst youths who sexually offend certainly confounds simplistic or binary understandings of the categories of victim and offender.

Acknowledgement of the complexities of responding to adjudicated youths with multiple and complex needs is longstanding. In 1997 the Australian Law Reform Commission identified significant concerns about the practices involved in sentencing children deemed to be vulnerable due to causes other than their contact with the law. ${ }^{17}$ Indigenous youths, those with cognitive delays or intellectual impairments and young people under state guardianship are but three particularly vulnerable groups requiring additional supports in their contact with the criminal justice system. The complexities of need experienced by young people in contact with the criminal justice system are charted in a recent study jointly undertaken by the New South Wales Department of Juvenile Justice, the University of Sydney and Justice Health. Assessing the physical and mental health of 800 young people serving community orders in NSW, this study

aimed to advance understanding of juvenile crime, its health, substance abuse and offence patterns, thereby facilitating effective policies and practices to reduce recidivism, improve health and create prosocial alternatives for young Australians at risk of a criminal career. ${ }^{18}$

\section{B Increasing Emphasis on Diversionary Options}

Australia is a party to several international instruments that require, inter alia, the prioritisation of diversionary and restorative justice options. ${ }^{19}$ In a move that is broadly in keeping with Australia's obligations under international law,

\footnotetext{
${ }^{17}$ The report makes a series of recommendations to support children with a mental illness, girls, Indigenous children and children who reside in remote areas and who, consequently, are far less likely to receive a non-custodial sentence. Australian Law Reform Commission, Seen and Heard: Priority for Children in the Legal Process, Report No 84 (1997) [19.93]-[19.116].

18 Dianna Kenny et al, Young Offenders on Community Orders: Health, Welfare and Criminogenic Needs (Sydney University Press, 2008) 1.3.

${ }^{19}$ Primary amongst these is the Convention of the Rights of the Child, of which articles 37 and 40 provide explicit requirements for member states in responding to children who enter the criminal justice system. Amongst other things, Article 37 requires that 'the arrest detention or imprisonment of a child shall be ... used only as a measure of last resort and for the shortest period of time:' United Nations Convention on the Rights of the Child, opened for signature 20 November 1989, 1577 UNTS 3 (entered into force 2 September 1990) ('CRC').
} 
the last two decades have seen an increase in the availability of diversionary options for juveniles who come to police attention for alleged breaches of the law. Since the 1990s each Australian jurisdiction has introduced alternative measures designed to divert children from formal involvement in the criminal justice system. Yet there is much disparity in the policy, practice and availability of diversionary schemes across, and between, each Australian state and territory. ${ }^{20}$ Harry Blagg uses the term 'justice by geography' to refer to the paucity of diversionary options available to children residing in regional and remote parts of Australia. ${ }^{21}$ The Australian Institute of Criminology reports that '[p]olice use of diversionary measures varies by sex, age, Indigenous status and jurisdiction' with between one-third and three-quarters of juveniles diverted away from the formal criminal justice system. ${ }^{22}$ There are also ongoing questions as to whether children who commit scheduled offences should be eligible for diversion, and whether there are racial and gender inequities inherent in the discretionary processes regarding cautioning, diversion and decisions to release children to the community on bail. ${ }^{23}$

\section{Is Restorative Justice an Option?}

In Australia, each state and territory offers restorative justice processes of some kind in an effort to divert juveniles away from the formal criminal justice system. At present, juveniles alleged to have committed sex offences (and other serious crimes) are ineligible for these diversionary programs in all states and territories except for South Australia and Queensland. Where such offences are reported to the police in other jurisdictions the only available options are for police to issue formal cautions and not proceed with charges,

\footnotetext{
${ }^{20}$ For example, Victoria places a strong emphasis on diversionary programs to avoid custodial terms. Victoria also has reverse onus provisions within its legislation that mean that bail should be granted unless there are persuasive reasons to the contrary.

${ }^{21}$ Harry Blagg, Crime, Aboriginality and the Decolonialisation of Justice (Federation Press, 2008) 67.

${ }^{22}$ Richards, above no 5, iii.

${ }^{23}$ There is not space here to discuss these alleged gender and racial and geographic biases in detail. For further information on the question of racial bias and the overrepresentation of Indigenous juveniles in detention see, eg, Lucy Snowball, 'Diversion of Indigenous Juvenile Offenders' (2008) 355 Trends and Issues in Crime and Criminal Justice 1; Blagg, above n 21; and Rick Sarre, 'Police and the Public: Some Observations on Policing and Indigenous Australians' (2005) 17(2) Current Issues in Criminal Justice 305. Importantly, Chris Cunneen contends that Aboriginal overrepresentation can not be conceived of in binary terms, as either a function of discrimination or of increased offending by Aboriginal people. He calls for a multifaceted understanding of this complex dynamic: Chris Cunneen, 'Racism, Discrimination and the Over-Representation of Indigenous People in the Criminal Justice System: Some Conceptual and Explanatory Issues' (2006) 17(3) Current Issues in Criminal Justice 329.
} 
or to charge the young person and initiate proceedings through the courts and the formal criminal justice system.

The vast majority of clinicians interviewed, including those in youth justice contexts, expressed the view that therapeutic counselling and diversionary schemes are preferable to custodial terms in most instances. In instances where an adolescent's sexually abusive behaviours are thought to pose an ongoing risk to the community there is the necessity to balance the therapeutic needs of the young person against concerns for the safety of others. In such cases clinicians identified the benefits of comprehensive therapeutic care for the young person in which, ideally, the family is involved and, where appropriate, the young person has the opportunity to understand their offence and their therapeutic work according to their own culture. This is the ideal scenario for young people with offending behaviour requiring a criminal justice response. Yet there are several barriers to ensuring this ideal outcome for all adjudicated young people.

\section{Few Convictions for Young People, and Program Eligibility Requiring Conviction}

The number of young people convicted of sex offences is very small. The processes that contribute to so few convictions for juvenile sex offenders are complex. The Victorian Law Reform Commission highlights the following challenges:

- prosecution necessitates that the complainant be a competent and credible witness;

- where complainants are too young to testify prosecution is unlikely;

- in cases of sibling abuse the family and the victim child are often unwilling to testify against the child displaying the abusive behaviours;

- there are general difficulties with the burden of proof, and;

- there is a perception that sexual assault by children and young people is less serious than that perpetrated by an adult. ${ }^{24}$

\footnotetext{
${ }^{24}$ Victorian Law Reform Commission, Sexual Offences: Final Report, (2004) 469.
} 
Increased conviction rates and custodial terms for juveniles with SABs are not advocated in any sphere. Yet clinicians expressed a series of complex concerns regarding young people who come into contact with the justice system but who, without a conviction, remain ineligible for the therapeutic responses made available by a court mandate. In several jurisdictions therapeutic services for adolescents are contingent on a conviction or a guilty plea.

Interviews for this study revealed concerns for young people who were charged with sexual offences but for whom the charges were pleaded down to lesser charges. Such practices preclude the young person's eligibility for mandated services. ${ }^{25}$ This is of particular concern in jurisdictions where there are few services for adolescents besides court-mandated services. Clinicians also expressed concern about services for young people who come to police attention, but who are cautioned rather than charged, or who are charged and the charges subsequently dropped. ${ }^{26}$

For example, if a young person is apprehended by police for their behaviours, and the charges are subsequently dropped or pleaded down, the young person is likely to be returned to their community. This is of particular concern in small communities, where people might generally be aware of the young person's police involvement. In small communities, including Indigenous communities, there is the risk that community divisions may arise as a result of the offence, and there is little in place to protect either the victim or the offender once the offender returns to the community. ${ }^{27}$ In such cases the young person's involvement with the law has a stigmatising effect, but no therapeutic follow-through. The young person may be at risk of retribution or ostracisation within their community, but they may also be at risk of reoffending, given that there has been no therapeutic intervention to address their behaviours. These same concerns would also apply to young people who are convicted of sex offences, but who are returned to their community to

${ }^{25}$ Interview with Mary-Culhane Brown (Department of Health and Families, Northern Territory, 17 July 2009).

${ }^{26}$ These concerns include those voiced by Victoria Police to the Advisory Committee for the Victorian Department of Justice's Sexual Assault Reform Strategy. These concerns have resulted in the funding of an additional 40 therapeutic places across the state for adolescents aged 15-17 who have sexually abusive behaviours: Interview with Janice Watt and Natasha Habjan (Sexual Assault Reform Unit, Department of Justice, 24 July 2009).

${ }^{27}$ Judy Atkinson, in particular, emphasised the need for extensive work with both the victims and the offenders in these circumstances: Interview with Professor Judy Atkinson (Gnibi College of Indigenous Australian Peoples, Southern Cross University, 16 April 2009); Interview with Louise Bromly and Sarah Dina (Department of Corrective Services, Juvenile Psychological Services, 6 May 2009). 
serve non-custodial orders. Both scenarios point to the importance of therapeutic work that is ecologically based - that is, counselling that is sensitive to (and actively involved with) the young person's familial and community contexts.

Moreover, there are concerns that young people who are not prosecuted 'are not afforded judicial safeguards that ensure that their rights will be protected.' The Australia and New Zealand Association for the Treatment of Sexual Abuse (ANZATSA) contend:

The absence of a judicial structure for making decisions often results in the most important decisions about a child or young person's mental state and risk of re-abusing being left to police officers or other government personnel. Such professionals are unlikely to have the expertise to make such assessments and the consequences of erroneous judgments may be lifelong for the child, young person and, not least of all, vulnerable members of the community. ${ }^{28}$

One of the primary concerns articulated by ANZATSA pertains to decisions to remove a young person from the family home. ANZATSA expresses concern that without the formal processes of review afforded by judicial decision making 'a situation of separation may go on indefinitely.' ${ }^{29}$ In general terms, ongoing separation from the family is likely to inhibit the young person's therapeutic gains, and further erode the positive attachments that are known protective factors. ANZATSA contends that failure to address the problem behaviour may 'result in the child or young person's prognosis deteriorating and exacerbating the risk of harm to others.' 30

\section{E Lengthy Remand Terms, and the Limited Referral Options Available to Magistrates}

Clinicians report therapeutic and ethical reservations about imposing offencespecific treatment prior to a young person being convicted of or pleading guilty to a sex offence. Moreover, each state and territory proscribes the provision of specialised sex offence counselling to young people prior to sentencing. This means that whilst a young person is on remand they are ineligible for counselling specific to their alleged offence, even if clinical staff

\footnotetext{
${ }^{28}$ Australia and New Zealand Association for the Treatment of Sexual Abuse, Submission to the National Indigenous Intelligence Taskforce of the Australian Crime Commission, 18 August 2009, 5.

${ }^{29}$ Ibid.

${ }^{30}$ Ibid.
} 
assess that there is a pressing need for therapeutic intervention. Several clinicians expressed concerns about lengthy remand terms and the consequences that these have for a young person's therapeutic care. ${ }^{31}$ Moreover, a study undertaken for the Queensland Department of Community Services found that delays in obtaining mental health and other court-ordered assessments can delay sentencing, in some cases by 12 months. ${ }^{32}$ Delays in evidentiary and legal processes and delays in securing sentencing dates are reported to be the major impediments here. In some instances the burden on youth justice psychologists, and/or the necessity to outsource to a private psychologist, might result in a further delay between the conviction and the commencement of therapeutic work. ${ }^{33}$

Indeed, sentencing and sentencing referrals were issues identified by several clinicians. The primary concerns were that, in several jurisdictions, magistrates had expressed frustration at the lack of referral options for young people charged with sex offences. In some jurisdictions this is simply because there are few referral options for non-adjudicated clients. This is a circumstance that Ian Berry, President of the Queensland Law Society (QLS) identifies as creating deficiencies in service response. Whilst Berry commends the provision of services for adjudicated clients in Queensland, he finds it 'unsatisfactory that adolescents must enter the criminal justice system in order to access treatment. ${ }^{34}$ Berry identifies the need for therapeutic services for young people to prevent them coming into contact with the criminal justice system.

Whilst referral options for police and magistrates are a source of concern, there is also a perception that justice workers would benefit from increased education and awareness regarding the complexities of adolescents with sexually abusive behaviours. In Tasmania, the Youth Justice Services team has identified a number of challenges in the pursuit of therapeutic jurisprudence, including the need to train magistrates about issues such as

\footnotetext{
${ }^{31}$ Interview with Ian Nisbet and Jeannette Liva (Department of Juvenile Justice New South Wales, 24 April 2009); Interview with Shirley Grace (Northern Territory Correctional Services, 16 July 2009); Interview with Culhane-Brown, above n 25; Interview with Rayment-McHugh, above $\mathrm{n} 3$.

32 Paul Mazerolle and Jennifer Sanderson, Understanding Remand in the Juvenile Justice System in Queensland (March 2008), Community Services Queensland, $38<\mathrm{http}$ ://www. communityservices.qld.gov.au/youth/publications/remand-report/>.

${ }^{33}$ Interview with Culhane-Brown, above n 25.

${ }^{34}$ Ian Berry, Queensland Law Society, Submission to the National Indigenous Intelligence Taskforce of the Australian Crime Commission, Australia's Response to Sexualised and Sexually Abusive Behaviours in Children and Young People, 7 September 2009, 1.
} 
sexualised behaviours, particularly where youth-specific courts are not available. $^{35}$

\section{F Services for Young People Convicted Of Sex Offences}

Each state and territory has provisions for youth justice clients serving custodial or community orders for sexually abusive behaviours. In each state and territory the governance arrangements differ, and the degree to which corrective services can offer specialised psychological supervision of an order also varies.

The broad challenge for all jurisdictions is how to cope with the practical difficulties of having a highly specialised psychological workforce travelling to service metropolitan, regional and remotely located youth justice clients. It is not surprising that the jurisdictions with the largest geographic areas face the most profound challenges, but this is not to say that the other states and territories don't experience difficulties in providing specialised supervision of community orders for young people charged with sex offences. At present the response model in each jurisdiction differs and, here, I'd like to touch on several initiatives that are currently striving to provide state-wide specialist services.

\section{$1 \quad$ Western Australia}

The Department of Corrective Services in Western Australia has an enormous geographic service area. The Department strives to provide psychological counselling for juvenile offenders in both community and custodial settings, whether convictions are for sex-specific or generalist offences. ${ }^{36}$ Departmental staff explained that whilst there are psychological services in place for young people in custodial settings, and for those within the inner metropolitan region, there are difficulties in providing services to those who are on community orders who reside some distance from Perth's centre. ${ }^{37}$

\footnotetext{
${ }^{35}$ Interview with Jennifer Thain (Youth Justice Services, Department of Health and Human Services, 20 March 2009) and subsequent submission to the National Indigenous Intelligence Taskforce of the Australian Crime Commission, Australia's Response to Sexualised and Sexually Abusive Behaviours in Children and Young People, 14 September 2009, 1.

${ }^{36}$ As with other jurisdictions, this occurs only when counselling is recommended in the psychological assessment prepared for court.

${ }^{37}$ Interview with Bromly and Dina, above n 27.
} 
As an accompaniment to individual counselling, the Department has now commenced group work with young people serving community orders for sex offences. For regionally or remotely located youth justice clients to access this service they would need to travel to metropolitan Perth, a circumstance that the Department acknowledges would likely be prohibitive.

Young people in the metropolitan area may also experience difficulties in accessing psychological services for specialised supervision of their order. The metropolitan area is approximately 90 kilometres wide and, under the Young Offenders Act 1994 (WA), young people can only be compelled to travel 30 kilometres for an order. ${ }^{38}$ For young people residing in regional areas, there are psychologists located in Albany, Geraldton and Kalgoorlie. However, there are a number of other locations in Western Australia in which access to a Department psychologist is not an option and thus young people convicted of sex offences who reside in these areas will serve the duration of their community order without receiving specialised psychological counselling to assist them in understanding the nature of their behaviours, or to deter them from recidivist offences.

The Department has taken steps to increase the delivery of specialised counselling in remote areas. In April 2008 the WA Department of Corrections established the 'Critical Response Team'39 following media coverage of juveniles charged with sex offences in Halls Creek. The mandate for this team was to provide psychological services to young people who were residing in the Kimberley region of WA and were serving community orders for sexual offences. This involved the preparation of psychological assessments for court reports, and departmental psychologists and the Aboriginal consultant travelling to relevant communities to provide psychological counselling to young people on orders. Part of this practice involved engagement with the school and, where possible, the young person's family. ${ }^{40}$ A psychologist from the Critical Response Team reported that there was also the opportunity to engage in prevention and early intervention work that was incidental to the primary purpose of their visit but nonetheless valued by the community. In one community the CEO, parents and the school expressed concern about the

\footnotetext{
${ }^{38}$ Young Offenders Act 1994 (WA) s 88(2) (available from www.slp.wa.gov.au). In the same provision, the Young Offenders Act also stipulates that the court cannot impose attendance conditions requiring offenders to attend an educational, rehabilitative, or other course for a period greater than 6 months. See also interview with Bromly and Dina, above $\mathrm{n} 27$.

39 This team comprised a Juvenile Justice Officer, a Community Corrections officer, two psychologists from Juvenile corrections, a program officer and an Aboriginal Consultant: Interview with Bromly and Dina, above $\mathrm{n} 27$.

${ }^{40}$ Staff from WA Psychological services reported that schools were generally very cooperative, but there were often challenges in effectively engaging families: ibid.
} 
sexualised behaviours of a group of six and seven year old boys. Coinciding with their scheduled visits every three or four weeks to supervise orders, Psychological Services began working with the young boys individually to deliver psycho-educational preventative messages.

Funding for the Critical Response Team was discontinued in April 2009, one year after the commencement of the service. ${ }^{41}$ Some positions within this team have remained, yet these fulfil administrative rather than therapeutic functions. The discontinuation of the outreach services of the Critical Response Team means that now, if a young person commits a sexual offence in a remote location in the north of the state, a psychologist will still travel to that location to prepare the assessment, but the report to court would be unlikely to make recommendations for treatment options. For a young person in this situation the likely therapeutic response would be limited to the basic psycho-sexual education that could be provided by juvenile justice officers located in country areas. ${ }^{42}$

\section{Queensland}

Queensland faces similar geographic challenges in delivering specialised services to remotely located youth justice clients. In response to this challenge the Griffith Youth Forensic Service (GYFS) has devised a unique field-based collaborative model of community outreach. ${ }^{43}$ GYFS is funded by the Queensland Department of Communities to provide specialist state-wide assessment and intervention services for those aged 10-17 who are convicted of sex offences. ${ }^{44}$ Based in Brisbane, and with a new satellite office in Cairns, GYFS has five full time (equivalent) therapeutic staff who service a geographic area stretching from the Gold Coast in the south of the state to the Torres Strait in the north. For a staff of this size to provide a state-wide service to all youth justice clients presents significant logistical challenges.

GYFS reports that it is consistently unable to meet the need for specialist service provision across the State. In light of this referral demand, GYFS and the Department of Communities have agreed to a protocol for prioritising referrals according to two key considerations. Firstly, clients with the greatest risk and criminogenic need are prioritised and, secondly, referrals for

\footnotetext{
${ }^{41}$ The team were funded to effectively conclude sessions with clients in instances where duty of care would prohibit a sudden termination of therapy: ibid.

${ }^{42}$ Juvenile justice officers are no longer required to be tertiary qualified, due to the difficulties in staffing country areas: ibid.

${ }^{43}$ See, eg, Smallbone et al, above $n 7$.

${ }^{44}$ GYFS also receives in kind funding and support from Griffith University.
} 
remotely located young people are prioritised over those from metropolitan areas. ${ }^{45}$ 'That is to say, priority is given to higher-risk cases, to more complex, higher-needs cases, and to cases where alternative services are less likely to be available. ${ }^{46}$ Consistent with these priorities, 85 per cent of GYFS clients are based outside of south-east Queensland and 40 per cent of current cases involve Indigenous youth. ${ }^{47}$ GYFS Manager Sue Rayment-McHugh reports that this prioritisation increases the workload for staff in two ways. Firstly, the greater the needs of and risks for the client the more complex and difficult the work and, secondly, the more remotely located the client the greater the demands on staff in terms of travel. ${ }^{48}$

The recently established GYFS office in Cairns aims to lessen the demand for staff to travel from Brisbane to far north Queensland and across Cape York. The intention is that Cairns will provide a base from which to increase the scope of services in North Queensland, particularly to Indigenous youth and their families in remote Cape York Communities. ${ }^{49}$ Fundamentally though, GYFS endeavours to meet the demand in regional and remote areas through its unique field-based model of collaborative partnerships through which it strives to build community capacity that will outlast the service that GYFS can provide.

Collaborative partners are identified on a case-by-case basis, following an assessment of the young person's sexual offending in the context of their unique social ecology, and typically include youth justice or mental health professionals, community counsellors, youth workers, or respected members of the local Indigenous community. ${ }^{50}$

This approach is highly individualised, and in each case the young person assists in identifying partners that can be engaged in their support. GYFS acknowledges that, whilst clinicians offer specialist psychological expertise in responding to sexual offending behaviours, they are not the only resource necessary to fully support the young person. The potential benefits of this model are that it:

\footnotetext{
${ }^{45}$ Interview with Rayment-McHugh, above n 3.

${ }^{46}$ Stephen Smallbone, Submission to the National Indigenous Intelligence Taskforce of the Australian Crime Commission, Australia's Response to Sexualised and Sexually Abusive Behaviours in Children and Young People, 7 August 2009, 2.

${ }^{47}$ Ibid.

${ }^{48}$ Interview with Rayment-McHugh, above $\mathrm{n} 3$.

${ }^{49}$ Submission from Smallbone, above n 46, 2.

${ }^{50}$ Smallbone et al, above n 7, 110 .
} 
- provides for continuity in the provision of services in regional and remote settings without the need for the continual presence of a specialised GYFS clinician,

- engages more broadly with the youth's natural social ecology, for example by including local responsible adults in the process of intervention and risk management, and

- builds the capacity of local professionals, paraprofessional and community members to respond effectively to present and future cases, by drawing on existing knowledge and skills and imparting new knowledge and skills. ${ }^{51}$

This is not to say that the GYFS team members do not identify challenges in their practice or in the state-wide provision of specialised services. Aside from the overwhelming demand for services, GYFS members articulate their concern that in some instances they are delivering therapeutic services to those who have sexually offended and yet there are no therapeutic services available to victims within that community. ${ }^{52}$ As with Victoria's Male Adolescent Program for Positive Sexuality (MAPPS), the services of GYFS are available only to those referred by the courts and Stephen Smallbone acknowledges that not all court-referred clients can be serviced by GYFS.

\section{The Northern Territory}

The Northern Territory's vastness also presents significant geographic challenges to the provision of specialised supervision to young people on youth justice orders for sex-specific offences ${ }^{53}$ Northern Territory Corrective Services (NTCS) are currently undergoing significant reform. Following a coronial inquest NTCS received funding to establish new positions and increase training to strengthen the community corrections response. Implemented in the last 18 months, these reforms mean that where youth justice orders were previously supervised by non-specialist and non-clinical staff, parole and probation officers can now work in consultation with the

\footnotetext{
${ }^{51}$ Submission from Smallbone, above $\mathrm{n} 46,3$.

${ }^{52}$ GYFS identifies this as a need not only to address the trauma experienced by victims, but also because although the precise link remains unclear "current evidence indicates that sexual victimisation is an important risk factor both for sexual behaviour problems in young people, and for sexual offending in adolescence and adulthood': Submission from Smallbone, above $\mathrm{n}$ 46,4 .

${ }^{53}$ Northern Territory Corrective Services (NTCS) report that 80 per cent of their clients are Indigenous. This refers to both adult and juvenile clients cumulatively: Interview with Grace, above $\mathrm{n} 31$.
} 
newly appointed intensive case managers. There are six positions within this new allocation and the intention is that these positions provide clinical support to the existing workforce of corrections officers who service youth justice clients, with outreach from key centres in the Territory. In response to Little Children are Sacred, the NT government provided \$4.4 million in additional funding to NTCS to expand sex offender services. This has allowed for the appointment of additional clinical staff within NTCS. These new clinical staff provide services to both adults and juveniles serving custodial sentences for sex offences. Prior to the establishment of this clinical workforce there were no specific violence or sex offender services at Don Dale, the Youth Detention Centre in Darwin. In the past, if therapeutic intervention was required for a young person the services of a private psychologist would be secured, or therapeutic counselling would be provided by the social worker employed by the detention centre.

In 2008, NTCS commissioned a report to inform the model for the delivery of therapeutic services to young people serving orders for sex offences in community settings. Professor Stephen Smallbone provided a report to NTCS in January 2009, and NTCS is now in the process of implementing a community-based model of therapeutic intervention that is similar to that utilised by GYFS in Queensland. Smallbone's report recommended that any sex offender treatment provided should 'acknowledge the diversity among the various language and cultural groups, and ... engage in meaningful and constructive ways not only with individual offenders but also with their families and their local communities. ${ }^{54}$ The model implemented by NTCS will provide therapeutic support for both adults and juveniles on orders, and will work with both the family and the community. The intention is to link the intensive case managers with generalist staff to ensure that services cover the geographic expanse of the Territory.

\section{CONCLUSION}

There are numerous challenges in ensuring equitable and comprehensive therapeutic services to custodial and community youth justice clients. Jurisdictions with the largest geographic service areas face enormous challenges in providing specialised supervision for community-based orders. This is perhaps the greatest challenge for the delivery of therapeutic services to youth justice clients. At present there are several jurisdictions where orders

\footnotetext{
${ }^{54}$ Stephen Smallbone, A Framework for the Development, Implementation and Evaluation of Sexual Offender Management and Treatment Programs in the Northern Territory (Griffith University, 2009) 17.
} 
for regionally and remotely located clients cannot include therapeutic provisions as there are no specialised staff to service those areas. This means that in some jurisdictions a young person convicted of a sexual offence will serve the duration of a youth justice order without receiving counselling to assist them in modifying their behaviours.

More positively, in several jurisdictions juvenile justice is undergoing significant reform. Efforts are focused on shifting dated and stigmatising organisational culture, recruiting qualified staff and funding best-practice programs that work with families and the child's ecology. In most jurisdictions there is an awareness that juveniles convicted of sex offences require a different therapeutic response from that traditionally offered to adult sex offenders. In instances where group programs are guided by written manuals, counselling staff generally expressed a desire to replace these with more individualised approaches. In each jurisdiction challenges persist, yet there is a cultural shift under way. Theoretically, increasingly nuanced and evidence-based understandings of young people's intersecting therapeutic, criminogenic and practical needs will ultimately contribute to an ongoing evolution of the dual youth justice and child protection response to young people who commit sex offences. Ideally, contact with either the criminal justice system or the statutory child protection system, or both, would facilitate a young person's access to the integrated services, supports and the specialised therapeutic care that will enhance their overall wellbeing and improve their outcomes for the lifecourse. This lofty goal is unlikely to be achieved if the emphasis is placed solely on containment, risk management, and punitive measures.

In closing I would like to return to the broader context of challenges identified in the national study. The report emphasises the importance of any response to sexualised behaviours being ecologically based. This necessitates a sensitive and integrated understanding of a child's context, with attention to their family life and their socio-economic circumstances, their peer group, the young person's physical, emotional and intellectual wellbeing, and the wellbeing of those around them. In truth this study is not only about the needs of children with sexualised behaviours; it highlights the need for integrated and holistic care for all Australian children who have experienced harm or adverse circumstances of any kind. Monopolising or 'siloing' responses by the criminal justice system, the statutory child protection system, allied health professionals or educational systems are unlikely to address the complexities of a young person's circumstances. A considered, committed and crosssectoral response is required to effect a reduction in the number of children who experience childhood trauma and subsequently enter the criminal justice system. 
I would also like to briefly underscore the national report's emphasis on educational strategies, particularly in the context of several Commonwealth government reports and inquiries that highlight the need for a national strategy for educational measures on youth violence. The national report identifies the need for comprehensive education strategies for parents and professionals in all related sectors in order to significantly improve and expedite children's pathways to specialised care. Moreover, the report highlights the importance of strategies to educate children and young people about the moral and ethical responsibilities of relationships, as a means of reducing harms, and reducing the number of juveniles detained on charges of sexual assault.

Indeed several recent inquiries and reports highlight the importance of educating young people about the legal and social consequences of their involvement in violent behaviours. One of the priorities of the Commonwealth Government's recently released National Strategy for Young Australians is establishing clear cut legal consequences for behaviours that endanger the safety of others. ${ }^{55}$ Similarly, the recent Parliamentary Inquiry into the impact of youth violence finds that although there is a large range of strategies and programs to target youth violence, these are not always rigorously evaluated, ${ }^{56}$ and "cannot be said to constitute a nationally cohesive youth violence prevention framework.' ${ }^{57}$ The inquiry acknowledges that escalating levels of youth violence will not be resolved by a single simplistic intervention, ${ }^{58}$ and calls for robust data-collection to 'help evaluate the efficacy of anti-violence interventions. ${ }^{59}$ This committee has recommended that 'the Australian Government conduct an audit of existing initiatives and programs that aim to address youth violence ${ }^{60}$ and work collaboratively to "establish a national youth violence and rehabilitation strategy to guide the provision of a holistic and integrated policy and program delivery framework. ${ }^{, 61}$

\footnotetext{
55 Commonwealth of Australia, National Strategy for Young Australians (2010) 3 $<$ http://www.youth.gov.au/bodyImage/Documents/NatStrat.pdf $>$.

${ }^{56}$ House of Representatives Standing Committee on Family, Community, Housing and Youth, above n 16, viii.

${ }^{57}$ Ibid 3.

${ }^{58}$ Ibid viii.

${ }^{59}$ Ibid 17.

${ }^{60}$ Ibid xv.

${ }^{61}$ House of Representatives Standing Committee on Family, Community, Housing and Youth, above $\mathrm{n} 16$, xiv.
} 
Recommendations such as these to increase the education of young people regarding violence and their responsibilities in conducting ethical relationships are broad primary prevention initiatives that may assist in reducing rates of victimisation. Theoretically, the provision of such primary prevention programs would ultimately necessitate fewer tertiary services for young people, and fewer places in juvenile detention centres. This is a desirable outcome. With international data estimating that between 40-90 per cent of sexual offences are perpetrated by children or adolescents, any reduction in juvenile sex offending would be valuable in lessening the impacts of the intergenerational cycle of victimisation and abuse and, ultimately, in reducing numbers of vulnerable young people entering the criminal justice system. 